\title{
Automated Bus Ticketing System
}

\author{
V. Priya, J. Dhanasekar, G. Vasumathi
}

\begin{abstract}
The regular traditional ticketing system originates with ticket papers dispensed by the staff conductor is replaced by the self-service vending machines. This replaced automated ticketing machine reduces the human work and make the ticketing system easier and used by all the people. This ticketing machine helps the people to easily print the ticket in one touch. The microcontroller that controls all the processes such like controlling the coin box and buttoning system, displaying the ticket and printing the ticket. The machine at the entry and exit end is operated with microcontroller. At the entry side the passenger can print the ticket in their own by selecting the starting and ending point then inserting the corresponding amount in the coin box. At the exit side the controller controls the driver control, display unit and the swiping section. The ticket should be swiped to get the door to open. This swiping section at the exit end helps to avoid cheating.
\end{abstract}

This system is additionally provided with the driver control where the driver of that bus has one control. The driver can indicate the current stopping point of the bus where it is in.

Keywords- Microcontroller, digital watches, Voltage Regulator, LCD, GPS, GSM, RFID

\section{INTRODUCTION}

This system is made as user friendly as possible so that anyone can use it with little knowledge of system computers. This system provides up-to date information that is not possible manually. All details about that bus route along with their corresponding ticket rates can be computed in that automated machine.

A computer based management system is designed to handle all the project primary information required to maintain the ticketing in bus. Ticket vending machine where the passenger can purchase a right to travelling ticket from self-serviced machine or to enquire the value of the ticket can be made possible with this method.

\section{WORKING METHOD OF EXISTING SYSTEM}

Ticket companion arrangement for the most part proposed to conquer the precarious issues in customary ticketing strategy like moving tickets starting with one individual then onto the next, sharing of tickets, to keep away from showdown for example work between the chiefs and travelers and more secure treatment of information. This framework present RFID innovation which totally kills the need of paper tickets.

Revised Manuscript Received on August 22, 2019.

V.Priya, Department of Mechatronics ,Bharath Institute of Higher Education \& Research,TamilNAdu Email: priyaygna14@gmail.com

J.Dhanasekar,, Department of Mechatronics ,Bharath Institute of Higher Education \& Research,TamilNAdu Email: Jdhanasekar81@gmail.com

G.Vasumathi Department of Mechatronics, Bharath Institute of Higher Education \& Research,TamilNAdu Email: vasu.bala06@gmail.com
Ticket well disposed machine holds the insights regarding the occasions given by advertisers, with the goal that shopper can buy tickets in their own record utilizing smartcards, Time and cash are valuable each time we endeavor to discover most ideal approach to keep away from issues in like manner. when it come to go by the transport without conveying change, this proposed system need just a single distinguishing proof card. In transportation, brilliant cards would turn into the following passage installment media supplanting or enhancing money, tokens and passes.

Brilliant cards or sticky cards is a chip card that contains an installed automated chip which is either a memory or microchip that stores and move information which improves the accommodation and security of any exchange and gives verification stockpiling of client and a record personality. Once if the traveler embed the brilliant card to ticket companion machine the RFID per user in shrewd card contains pay mode terms, which check for the sum in the record. This installment framework naturally energizes all pre-issued card with the sum favored by the approved individual and furthermore when the individual used to examine the card. [1],[3],[5]

In the wake of getting subtleties from RFID, Zigbee transmits the information of vehicle offices through enormous showcase. Zigbee is frequently used to transmit information over long separation by going information through moderate gadgets which gives a safe system process. Constant transport data framework (RTBIS) may likewise utilized in this framework that utilizations satellite innovation to foresee the hour of transport which will touch base at a stop. RTBI can be get from electronic presentations at bus stop and stops.

The information's identified with transport courses alongside transport charges and seats accessible in the transport will be shown on the presentation of the machine make the traveler to pick or book the tickets with more care. In the wake of booking the tickets, through [2],[4],[6]

GSM the information identified with traveler booking will be gotten by the GSM existing in the transport that guarantees the transport administrator to get the insights concerning travelers area. At the same time after the information is chosen by the traveler, RFID peruser prints the security code on the shrewd card. This card once more become an entryway to go into the transport, gave brilliant detecting component. When the code made by RFID is detected then the entryway gets opened naturally. 


\section{PROPOSED WORK}

The PIC microcontroller is used to control other units. It replaces the traditional paper ticketing method by embedded system. To make sure that no person is escaping without tickets, we use ticket checking system at the exit side. There is no possibility for every one to have an bank account to access wit smart card technology. [7],[9], [10]

\section{A. BLOCK DIAGRAM}
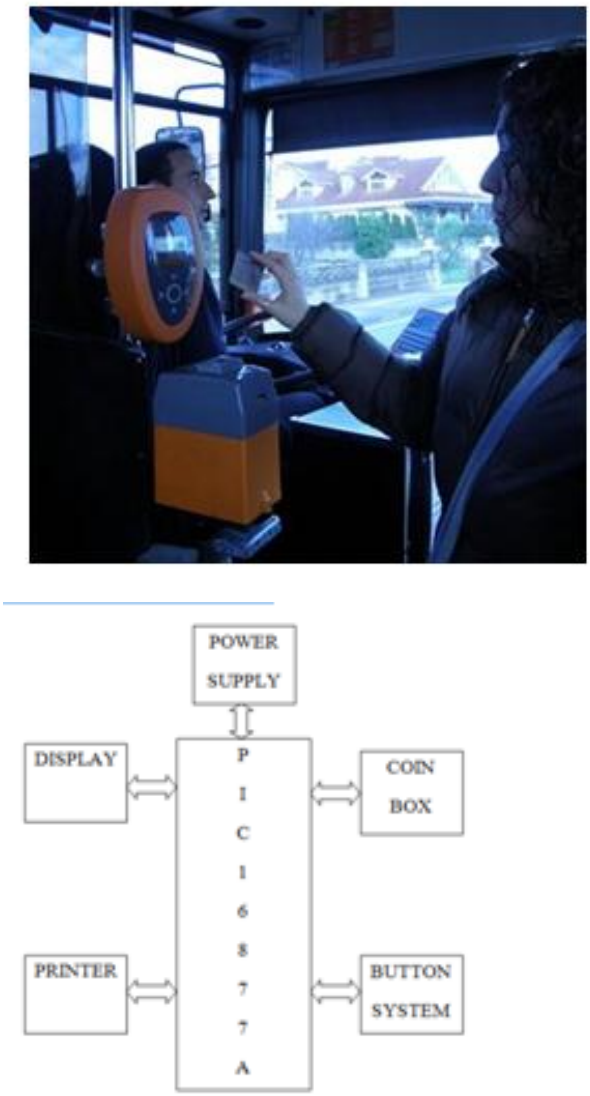

Fig 2 (block at entry side)

\section{B. BLOCK DIAGRAM EXPLANATION}

The pic controller controls all other blocks. When the passenger enters into the bus selects the starting point where they get into the bus and the destination point where they want to get down in the button system. Then the corresponding charge is displayed in the display unit. The passenger then drops the amount in the coin box. So that the printer prints the ticket.

\section{BUTTON SYSTEM}

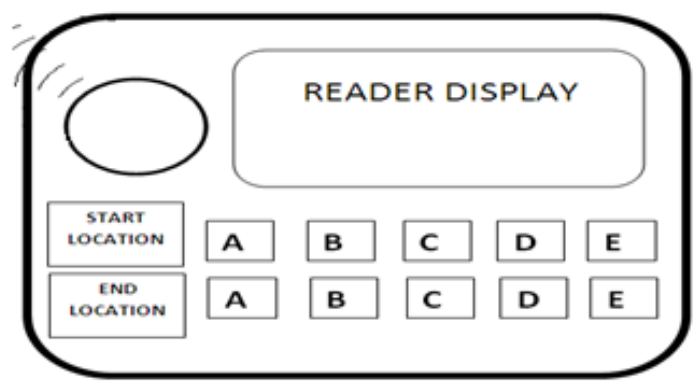

Fig 3Button Display
The button system allows to select start and end location that the buttons A, B, C, D, E indicates the locations where the bus stops in that route. The reader display in this system displays the passengers selection. The buttons A, B, C, $\mathrm{D}, \mathrm{E}$ in start and end location are the same.

\section{DISPLAY BLOCK}

The display unit displays the start location, end location and the rate of the ticket choosed by the passenger. The passenger can enquire for the rates of the ticket which can be displayed on the display unit.

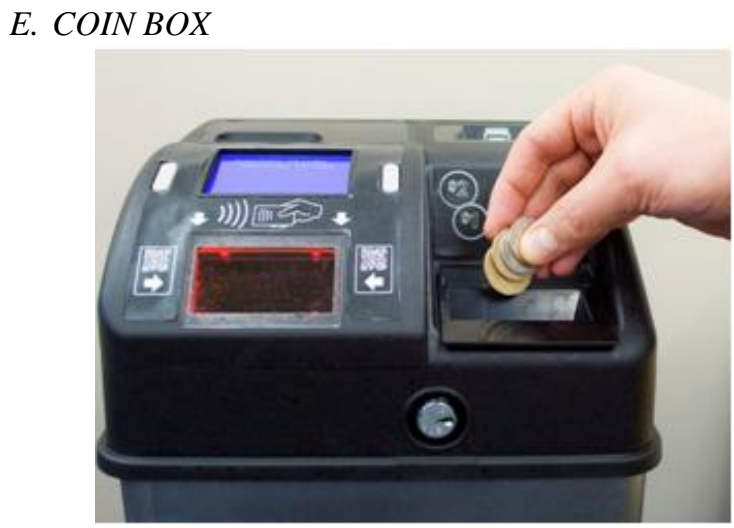

Figure 4 Coin Box

The coin box is similar to the one rupee coin telephone. The passenger should drop the corresponding ticket amount in that box so that the ticket is printed. There are separate insert coin boxes to drop one, two, five and ten rupee coin. There is also possibility to keep the rupee note inserting box. This system helps to insert coin whereas in existing system there is a use of smart card so that the passenger have the bank account which is similar to the atm card.

\section{F. PRINTER BLOCK}

The printer unit is just to print the ticket what displayed in the display unit. The printed ticket has the details of start and end location, ticket rate and number of passengers.

\section{G. BLOCK DIAGRAM}

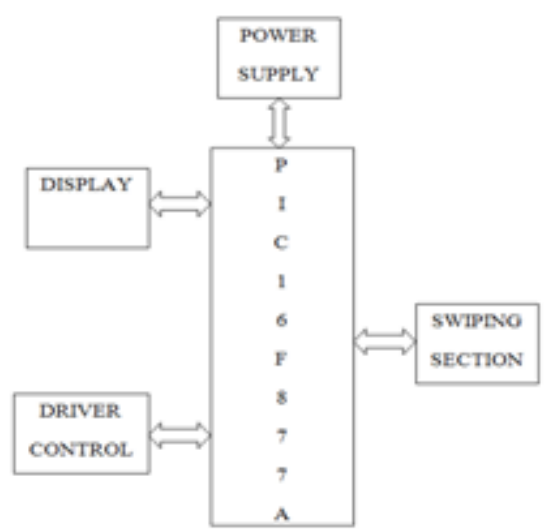

FIG 5(Block at Exit side)

Published By:

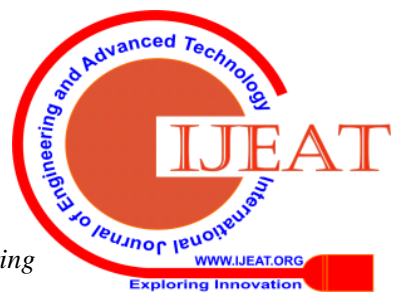


At the exit side the passenger should be needed to swipe the ticket in the swiping section to get the door to be opened. The display shows the condition of the door whether the door is opened or closed. The driver control has the control connected to the driver who can indicate the current place of the bus where it is in. The pic microcontroller controls all the units connected to that as the program is dumped to do the required process.

$H$.

\section{Swiping Machine}

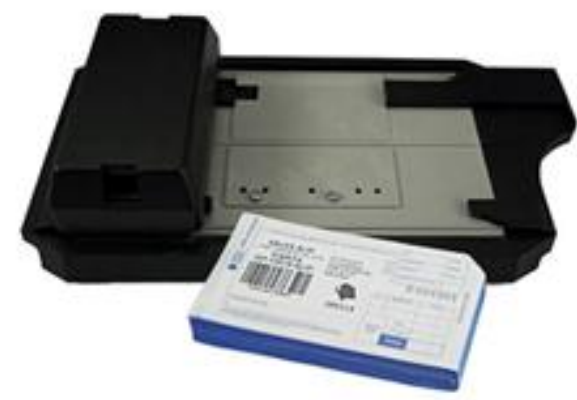

FIG 6:Swiping Machine

In the swiping section passenger should swipe the ticket to get the door to be opened. The number passengers getting out of the bus is sensed by the sensor. So there is no way of cheating. If there is any problem in the existing of the number of passengers it is indicated to the driver through the driver control.

\section{DRIVER CONTROL}

The driver control at other end is connected to the driver so that the driver can indicate the current location of the bus stop. If the is any problem with the number of existing passengers it is indicated to driver

\section{J. DISPLAY BLOCK}

The display block at the exit side is to only display the condition of the door whether it is opened or close. After swiping the ticket the display unit displays open and after the existence of the passenger it shows close.

\section{CONCLUSION AND FUTURE WORK}

In the existing system every passengers who travel in bus need the bank account. The current framework depends on the idea of programmed ticket candy machine by utilizing RFID and Zigbee technique.Ticket amicable arrangement through robotized machine empowers the traveler to foreordain the vehicle details.In this computerized framework we supplant the customary ticket framework by keen card that contains all subtleties of the client including ledger data, which is like the ATM card. In our proposed system there is noo need of smart card as it replaced by the coin box. The main advantage of this proposed system is the automated ticket machine is placed inside the bus so the passenger can print their own ticket after getting into the bus.

\section{REFERENCES}

1. Dhanasekar, J., Sengottuvel, P. \& Palanikumar, K. 2019, "Implementation of effective fuel saving methodology for turbines using air drag in vehicles", Materials Today: Proceedings, pp. 421

2. Kumar, S.S., Kumar, K.S.R. \& Kumar, N. 2018, "Experimental evaluation of magnetorheological damper characteristics for vibration analysis", International Journal of Vehicle Structures and Systems, vol. 10, no. 1, pp. 30-34.

3. Dhamodaran, K., Adikesavana, P., Shankar, P.P. \& Gowtham, S. 2018, "Conceptual development of flapping wing for unmanned aerial vehicles: Technical note", International Journal of Vehicle Structures and Systems, vol. 10, no. 1, pp. 43-45.

4. Karthikeyan, S., Raman Balasubramanian, S.R., Ramesh, B., Raghul, S. \& Sathish Kumar, S. 2019, "The automatic solar tracker chronicles", International Journal of Recent Technology and Engineering, vol. 8, no. 1, pp. 312-315.

5. Hema, R., Sundararajan, M. \& Balaji, S. 2019, "Smartphone control robot with automatic firing gun", International Journal of Innovative Technology and Exploring Engineering, vol. 8, no. 9 Special Issue 3 , pp. 625-627.

6. Balambica, V., Deepak, V. \& Kumar, S. 2019, "Design and efficiency of an asymmetric gear", International Journal of Mechanical and Production Engineering Research and Development, vol. 9, no. 3, pp 223-230.

7. Saravana, S., Balaji, S., Arulselvi, S. \& John Paul Praveen, A. 2019, "Reliable power quality monitoring and protection system", International Journal of Innovative Technology and Exploring Engineering, vol. 8, no. 9 Special Issue 3, pp. 644-645.

8. Bycil, V.J. \& Wiselin, M.C.J. 2019, "Modeling and analysis of vibration energy harvesting system using piezo stack", International Journal of Mechanical and Production Engineering Research and Development, vol. 9, no. Special Issue 1, pp. 523-533.

9. Sripada, A., Warrier, A., Kapoor, A., Gaur, H. \& Hemalatha, B. 2018 , "Dynamic lateral balance of humanoid robots on unstable surfaces", International Conference on Electrical, Electronics, Communication Computer Technologies and Optimization Techniques, ICEECCOT 2017, pp. 539.

10. Mahalakshmi, V. \& Vijayaragavan, S.P. 2019, "PV based power electronic converters for high voltage DC applications", International Journal of Recent Technology and Engineering, vol. 7, no. 6, pp 670-674.

\section{AUTHORS PROFILE}

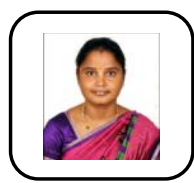

Priya V Assistant Professor,Department of Mechatronics Bharath Institute of Higher Education \& Research,TamilNAdu

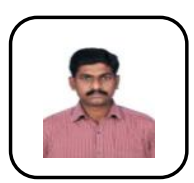

Dhanasekar. J,

Assistant Professor,Department of Mechatronics Bharath Institute of Higher Education \& Research,TamilNAdu

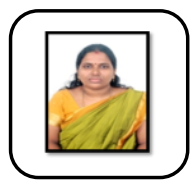

Vasumathi. Assistant, Professor,Department of Mechatronics Bharath Institute of Higher Education \& Research,TamilNAdu 